Civil-Comp Press, Stirling, Scotland.

\title{
A Parametric Study of the Non-Linear Geometric Behaviour and Carrying Capacity of 3D Asymmetric Steel Frames
}

\author{
M.B. César† and R.C. Barrosł \\ $\dagger$ Escola Superior de Tecnologia e de Gestão, \\ Polytechnic Institute of Bragança, Portugal \\ $\$$ Department of Civil Engineering \\ University of Porto, Portugal
}

\begin{abstract}
Non-linear P-delta behaviour of three-dimensional frames with plan and elevation asymmetries is studied, using a parametric variation of geometry in plan and a stiffness variation along the height. Some behavioural aspects of a calibration frame have been addressed to ascertain the importance of the nodal rigidity, modelled with laminar elements of the type shell with implicit formulation of thick plate or modelled with elastic stiff springs, in the study and modelling of the geometric nonlinearity and stability of such calibration frame. Eurocode 3 criteria for second order analyses is briefly addressed in connection with the 2D frame classification with respect to sway behaviour; however for $3 \mathrm{D}$ structures the calculated carrying capacity is independent of this classification. So a parametric study of the critical load factor of asymmetric three-dimensional frames, un-braced and braced, permits to characterize their carrying capacity with respect to overall structural stability.
\end{abstract}

keywords: non-linear geometric structural analysis, stability of asymmetric 3D frames, bracing of structures, modelling of connections.

\section{Introduction}

Tall three-dimensional irregular or asymmetric steel frames often have their design controlled by structural stability requirements [1].

This study departs from previous works of the authors (Cesar and Barros [2], Barros and Cesar [3]) that used a calibration frame for assessing the validity and accuracy of some available commercial software (namely ANSYS [4], LUSAS [5] and SAP 2000 [6]) as well as of the authors developed software INST3D (Barros and Cesar [7]) in determining the critical load factor of side-sway prevented and side-sway free frames; thereafter INST3D, ANSYS and SAP were used concurrently in characterizing the non-linear carrying capacity of 3D metallic frames (braced and unbraced) with plan asymmetries. 
The present work starts by addressing two modelling aspects of the nodal connections between adjacent members (beams and columns) of the structural steel framework. The behaviour of a calibration frame is ascertained for the nodes modelled (in a macro-zone) using shell elements in different configurations, as well as for the nodes modelled as (point) elastic springs with increasing stiffness. Coherence of both formulations was found, as the node stiffness increases. The importance of the two modelling cases, bounding non-linear carrying capacity of the calibration frame, is assessed. Thereafter, the main emphasis of this work is on parametric studies of the non-linear geometric behaviour and carrying capacity of 3D asymmetric steel frames, with plan and elevation asymmetries.

Before addressing some modelling aspects of the nodal connections between adjacent members of the structural steel framework, the numerical results of a calibration frame represented in Figure 1 - analytically solved by Reis and Camotim [8] and computationally solved by Cesar and Barros [2] Barros and Cesar [3] using INST3D (with exact total stiffness formulation) - are presented in graph form (Figure 2). Such graphs enhance the path of the convergence process of the critical buckling load evaluated with three distinct software (ANSYS, LUSAS, SAP), for sidesway prevented frame (or un-displaceable joints) and for sidesway free frame (or displaceable joints), under successively refined finite element discretization of the structural members.

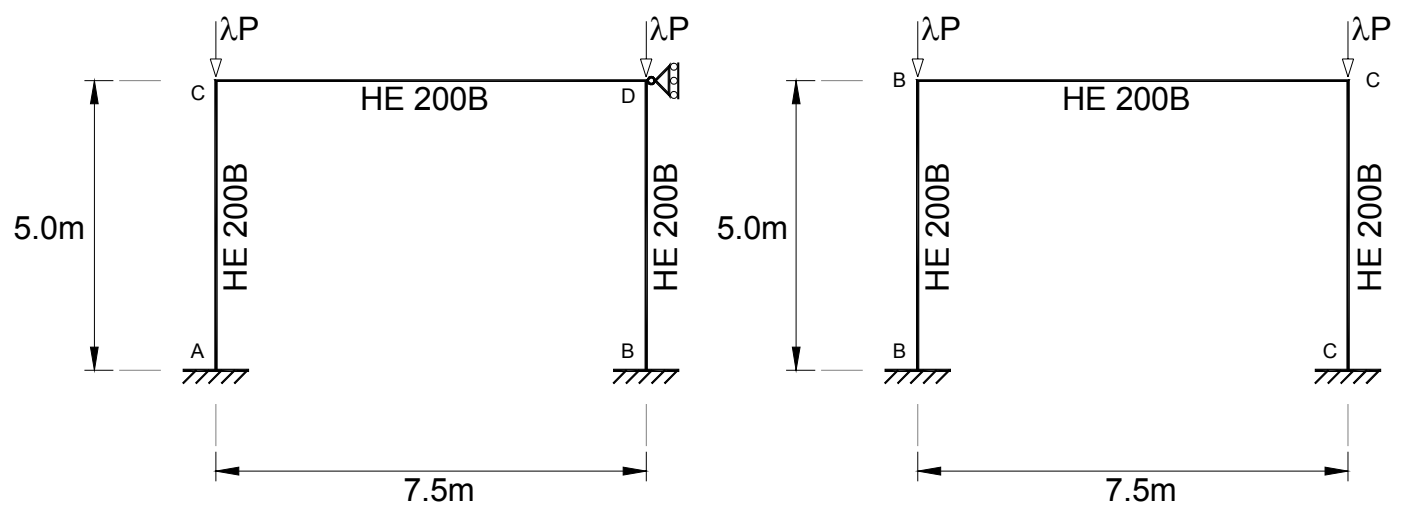

Figure 1: Calibration frames (left: sidesway prevented; right: sidesway free)
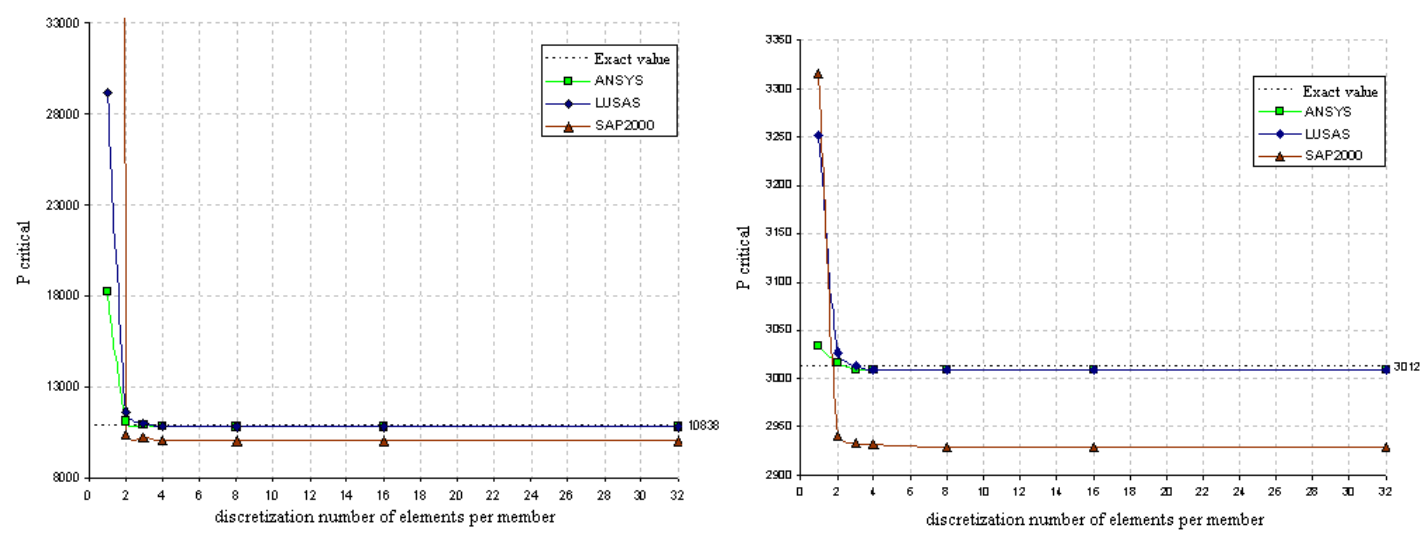

Figure 2: Critical buckling load of the calibration frame (left: sidesway prevented; right: sidesway free) $v s$ discretization number of finite elements per member 
ANSYS software gave the best results, with a relative error less than $1 \%$ for a 3 element discretization per member. LUSAS gave the same results for 4-8 element discretization; for same discretization, SAP 2000 underestimated results within 7\%.

\section{Some Behavioural Aspects of the Calibration Frame}

\subsection{Modelling of Nodes with Shell Elements}

Structural modelling plays an important role in this type of analysis, particularly in cases of local phenomena of strength and stability or to model rigidity of the linking zones at the connection nodes. In this last case, it is sometimes necessary to appeal to three-dimensional modelling to obtain a more realistic knowledge of the functioning of the linking.

To analyze the importance of the nodal rigidity form in the study of the geometric non-linearity and stability of the calibration frames, the members of the frames shown in Figure 1 were modelled by Cesar [9] with laminar elements of the type SHELL with implicit formulation of thick plate, using the commercial software SAP 2000. The geometry of the shell elements to be used in the FEM is defined in function of the thickness of the web and flanges of the metallic member profile HE 200B. Figure 3 represents the discretization model of the shell finite elements for the sections of the commercial profile, used as members of the calibration frame.

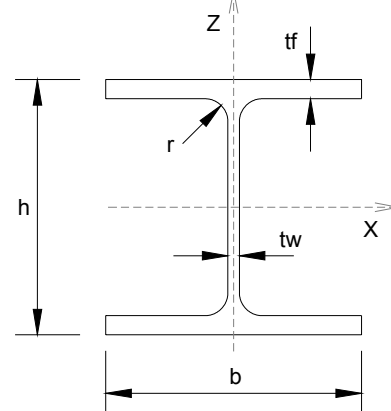

HE 200B

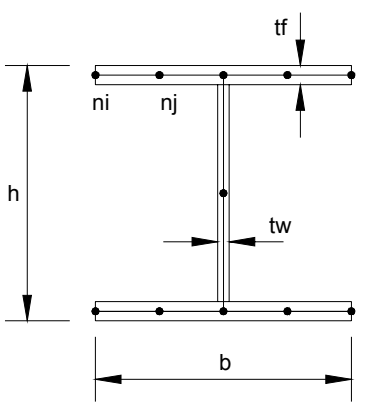

SAP 2000 (SHELL)

Figure 3: Profile HE 200B and equivalent SHELL finite element

The discretization of the shell elements was chosen after having done several subdivisions of these elements, in order to get convergent results. The reference calibration frames were subdivided in 478 elements and was used a relative error tolerance of $10^{-7}$ for determining the critical load parameter. The plane steel frames with the geometric characteristics $(\mathrm{L}=5.0 \mathrm{~m} ; \mathrm{H}=7.5 \mathrm{~m})$ shown in Figure 1, and elasticity modulus $\mathrm{E}=200 \mathrm{GPa}$, have been studied in their plan without possibility of loss of stability in the perpendicular direction.

In the modelling, the shell elements of the column present continuity in the union with the shell elements of the beam. In reality it is possible to materialize this type of linking in metallic structures through the use of parts joined by welding. To guarantee the continuity it is common to introduce reinforcement elements at the linking through added metallic plates, also simulated with SHELL elements of SAP. 
Modifying the characteristics of the linking at the union of beam to column, one proves that the rigidity of these zones influences the performance of the structure.

(i) Sidesway prevented (or un-displaceable joints) calibration frame

The modelling of rigid nodes through added metallic reinforcement elements leads to lower buckling loads than assuming full continuity at the node section. This fact is due to the introduction of the form of the element in the modelling, diminishing the resistant capacity of the element due to loss of geometry of the section. Figure 4 shows five types of successively stiffer connections modelled with laminar shell elements, and for each type the first six buckling load parameters were determined with SAP 2000. The results of the analysis with elements of the type SHELL lead to lower values of the buckling load parameters $\lambda$, namely of the first or critical value $\lambda_{\text {cr }}$, what could be expected in view of the possibility of alteration of the space geometry of the sections of the beam and of the column.
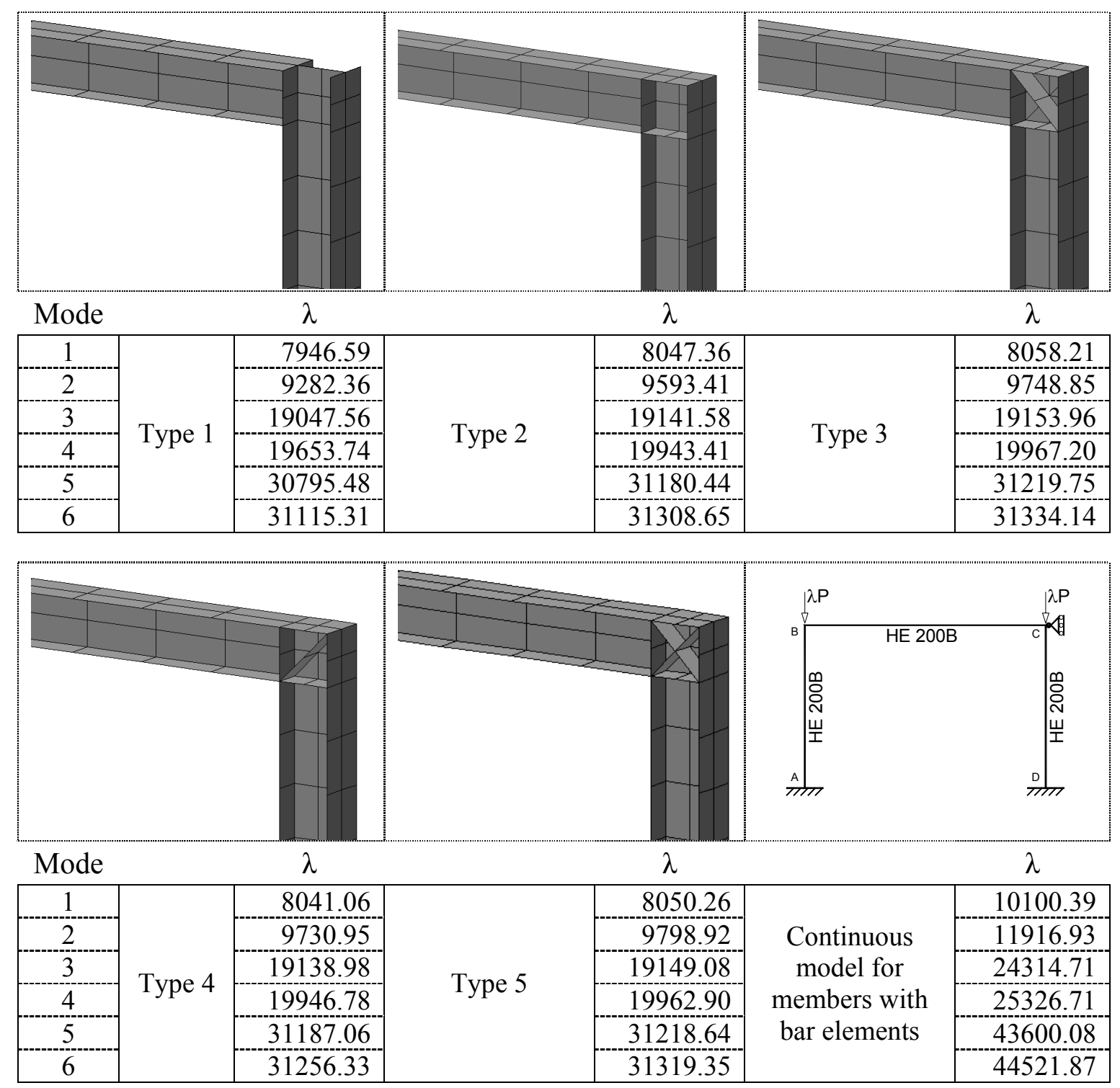

Figure 4: Buckling load parameters (up to $6^{\text {th }}$ mode) for sidesway prevented frame 
The relative error of $20 \%$ for the critical buckling load (in configuration type 5), relatively to the continuous model of members with bar elements, indicates that some care must be taken in the determination of the critical load parameter when nodal continuity is based upon added metallic reinforcement plates.

(ii) Sidesway free (or displaceable joints) calibration frame

The same study was elaborated for the sidesway free calibration frame, with the five configurations of plate reinforcements as used in the sidesway prevented frame.

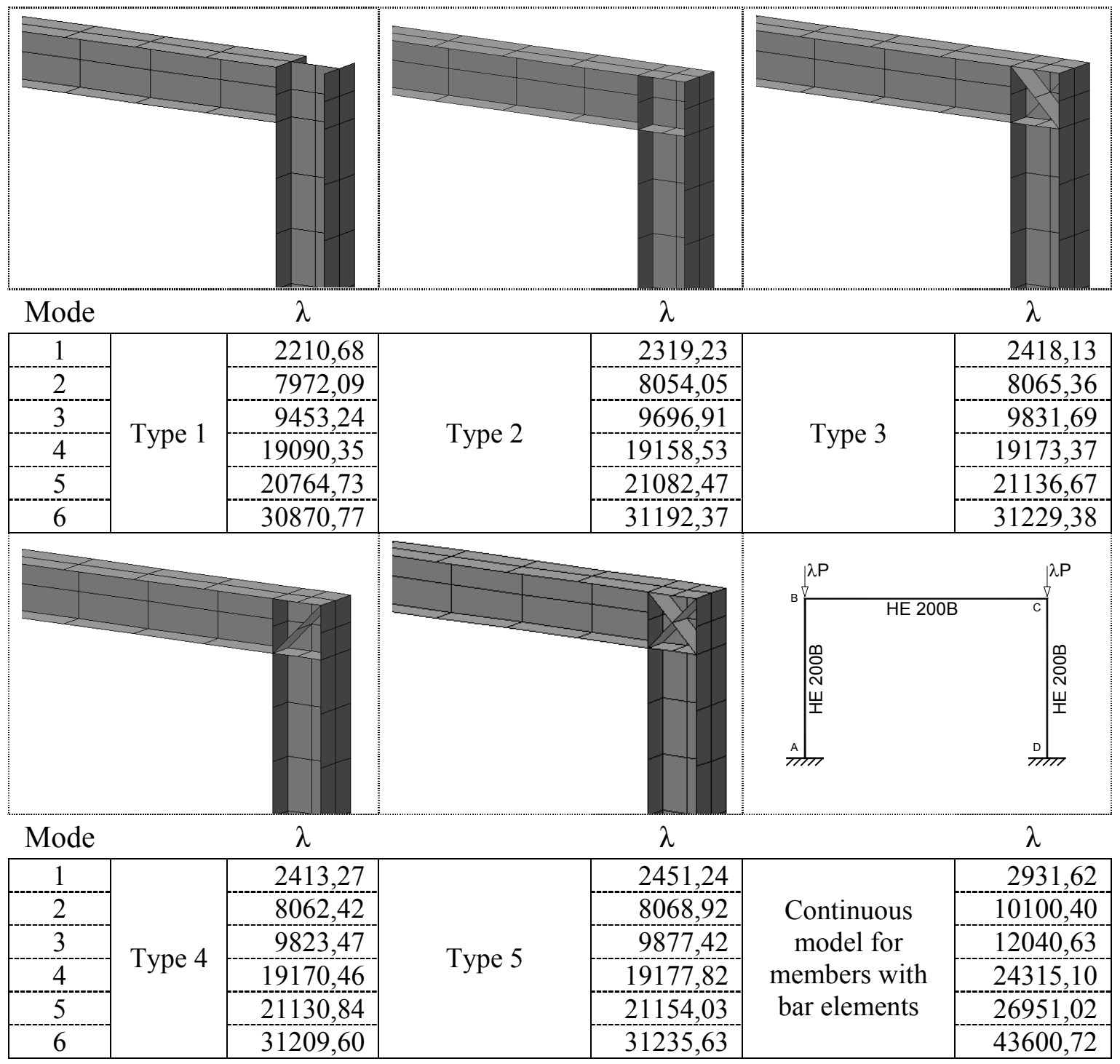

Figure 5: Buckling load parameters (up to $6^{\text {th }}$ mode) for sidesway free frame

In Figure 5 the five nodal rigidity configurations studied are presented, with each of the results obtained for the first six buckling load parameters. The relative error of $16 \%$ for the critical buckling load (in the stiffer configuration type 5), relatively to the continuous model of members with bar elements, coherently confirms the importance of modelling nodal continuity especially in simplified models. 
When the nodal rigidity is increased in both cases of sidesway prevented and sidesway free frames, the results obtained for the calibration frames with elements of area of the type SHELL (thick plate) tend for the results of the analysis associated with a continuous model in which the structural members are subdivided (using ANSYS, LUSAS or SAP 2000) in bar elements; so, ultimately tend for the results of the analysis with an exact total stiffness matrix formulation (as used in INST3D) as emphasized by Cesar and Barros [10].

\subsection{Modelling of Nodes with Stiff Elastic Springs}

In the previous case, the nodal rigidity configuration was introduced at the connection of beam to column. A simplified model can be used with three types of boundary conditions in the link between beam and column bars: full continuity, pinned and (point) elastic rotation springs. The link with springs corresponds to an intermediate situation where the connection presents a partial rigidity, with rotation capacity and moment transmission dependent on the stiffness of the spring.

The application of this model, that also approaches reality, requires the calibration or selection of the spring stiffness that better simulates the connection. Figure 6 presents the calibration frames with the addition of rotation springs to simulate the elastic flexible behaviour of the beam to column connections.

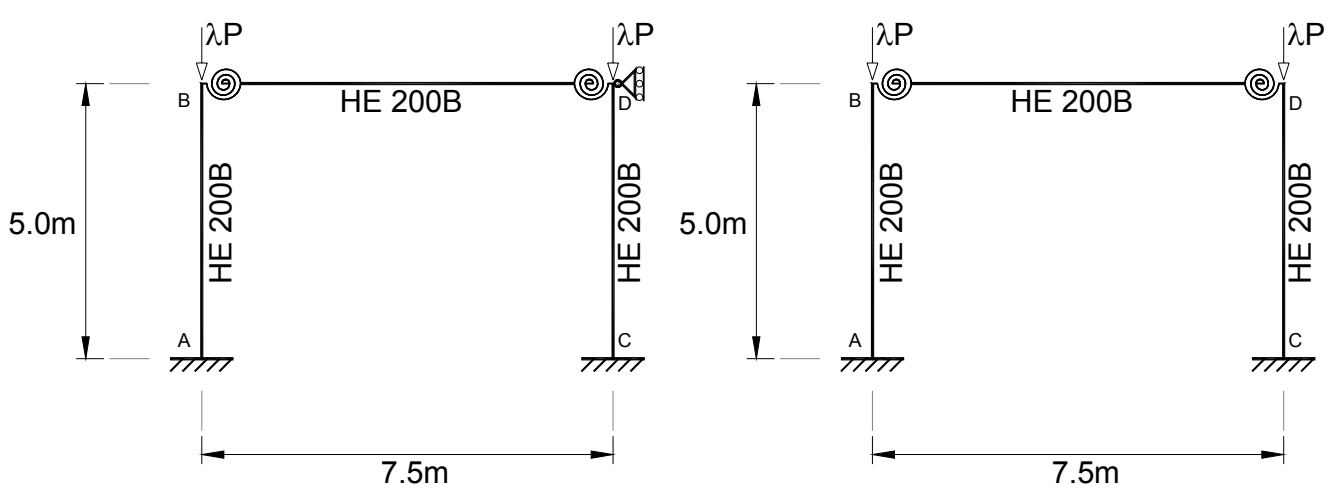

Figure 6: Calibration frames with elastic springs at the beam to column connections (left: sidesway prevented; right: sidesway free)

These frames have been modelled in SAP 2000 by Cesar [9], considering as valid standard a reference discretization of 4 elements per member. The spring stiffness $\mathrm{k}$ varied from 0.0 , corresponding to a pinned connection, until a stiff value of $10^{10}$ to which is associated the same results as for a full continuous connection.

(i) Sidesway prevented (or un-displaceable joints) calibration frame

The computational importance of the number of elements discretization per member, in the evaluation of the buckling loads, is shown in Table 1. Such results have already been synthesized in Figure 2 .

In Table 1 are emphasized the results for the subdivision of the members in 4 elements, to which should correspond a determination of the critical buckling load with a relative error inferior to $3 \%$ in relation to the exact value $\left(\lambda_{\text {cr }}\right)$. 


\begin{tabular}{|c|c|c|c|c|c|c|c|}
\cline { 3 - 4 } \multicolumn{1}{c|}{} & \multicolumn{7}{c|}{ Discretization number of elements per member } \\
\hline Mode & 1 & 2 & 3 & 4 & 8 & 16 & 32 \\
\hline 1 & 18347.35 & 10408.73 & 10184.58 & 10100.39 & 10032.21 & 10017.78 & 10014.35 \\
\hline 2 & 27455.56 & 12192.52 & 12036.15 & 11916.93 & 11815.15 & 11793.13 & 11787.88 \\
\hline 3 & 933285.30 & 35459.41 & 25022.30 & 24314.71 & 23446.21 & 23250.05 & 23202.96 \\
\hline 4 & --- & 39321.50 & 25805.53 & 25326.71 & 24435.60 & 24224.52 & 24173.52 \\
\hline 5 & --- & 104942.05 & 64077.00 & 43600.08 & 40801.41 & 39836.47 & 39602.25 \\
\hline 6 & --- & 120871.95 & 68928,41 & 44521.87 & 42188.33 & 41172.63 & 40923.70 \\
\hline
\end{tabular}

Table 1: Buckling loads evaluated for distinct discretization of elements per member

In Table 2 and Figure 7 the values of the first six buckling loads are presented in tabular and graphical forms, in function of the model spring stiffness used.

\begin{tabular}{|c|r|r|r|r|r|r|c|}
\cline { 2 - 8 } \multicolumn{1}{c|}{} & \multicolumn{7}{c|}{ Stiffness k of the elastic spring $(\mathrm{kN} . \mathrm{m} / \mathrm{rad})$} \\
\hline Mode & $\mathrm{k}=0.0$ & $\mathrm{k}=1.0$ & $\mathrm{k}=10^{2}$ & $\mathrm{k}=10^{4}$ & $\mathrm{k}=10^{6}$ & $\mathrm{k}=10^{10}$ & $\mathrm{k}=\infty$ \\
\hline 1 & 8631.41 & 8631.98 & 8686.61 & 9800,51 & 10096.64 & 10100.39 & 10100.39 \\
\hline 2 & 8638.65 & 8639.21 & 8693.79 & 10730,13 & 11898.71 & 11916.93 & 11916.93 \\
\hline 3 & 23692.98 & 23693.19 & 23713.43 & 24177,16 & 24312.95 & 24314.71 & 24314.71 \\
\hline 4 & 23713.70 & 23713.91 & 23734.34 & 24628,24 & 25314.72 & 25326.71 & 25326.71 \\
\hline 5 & 43005.57 & 43005.77 & 43025.24 & 43472,66 & 43598.46 & 43600.08 & 43600.08 \\
\hline 6 & 43051.88 & 43052.08 & 43071.28 & 43887,84 & 44510.98 & 44521.87 & 44521.87 \\
\hline
\end{tabular}

Table 2: Dependence of buckling loads of the sidesway prevented frame on spring stiffness of the connections (subdivisions of 4 elements per member)

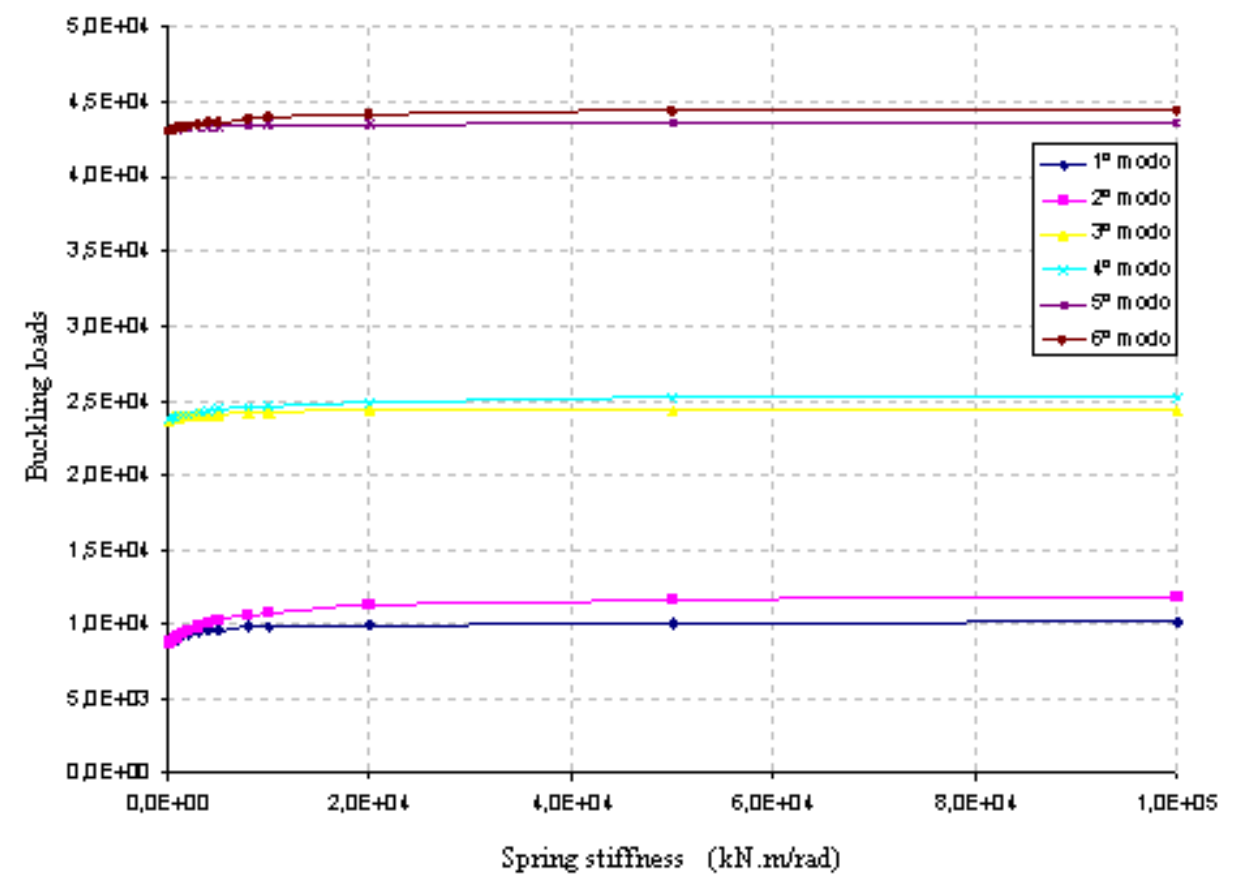

Figure 7: Buckling loads of sidesway prevented frame vs spring stiffness of the beam to column connections 
For lower spring stiffness the graph emphasizes a non-linear initial behaviour of the frame carrying capacity for distinct buckling modes as stiffness increases, nevertheless approaching an almost constant value of the buckling loads for higher spring stiffness. The gain in carrying capacity for the critical mode of this undisplaceable joints frame as stiffness increases is smaller than $15 \%$; indirectly this may be considered as an upper bound on the gain in carrying capacity for this sidesway prevented frame, if semi-rigid connections would have been modelled for the links between the beam and the columns (Cesar and Barros [10]).

(ii) Sidesway free (or displaceable joints) calibration frame

The computational importance of the number of elements discretization per member, in the evaluation of the buckling loads of the sidesway free frame, was synthesized in Figure 2. In Table 3 and Figure 8 the first six buckling loads are given in tabular and graphical forms, in function of the model spring stiffness used.

\begin{tabular}{|c|r|r|r|r|r|r|r|}
\cline { 2 - 9 } \multicolumn{1}{c|}{} & \multicolumn{7}{c|}{ Stiffness $\mathrm{k}$ of the elastic spring $(\mathrm{kN} \cdot \mathrm{m} / \mathrm{rad})$} \\
\hline Mode & $\mathrm{k}=0.0$ & $\mathrm{k}=1.0$ & $\mathrm{k}=10^{2}$ & $\mathrm{k}=10^{4}$ & $\mathrm{k}=10^{6}$ & $\mathrm{k}=10^{10}$ & $\mathrm{k}=\infty$ \\
\hline 1 & 1115,43 & 1115,83 & 1154,02 & 2376,82 & 2923,86 & 2931,62 & 2931,62 \\
\hline 2 & 8635,04 & 8635,61 & 8689,63 & 9800,52 & 10096,65 & 10100,40 & 10100,40 \\
\hline 3 & 9516,55 & 9516,90 & 9551,41 & 11024,66 & 12024,31 & 12040,63 & 12040,63 \\
\hline 4 & 23703,45 & 23703,66 & 23723,78 & 24177,71 & 24313,33 & 24315,10 & 24315,10 \\
\hline 5 & 24617,62 & 24617,91 & 24646,44 & 25929,22 & 26933,32 & 26951,02 & 26951,02 \\
\hline 6 & 43029,17 & 43029,37 & 43048,49 & 43473,88 & 43599,10 & 43600,72 & 43600,72 \\
\hline
\end{tabular}

Table 3: Dependence of buckling loads of the sidesway free frame on spring stiffness of the connections (subdivisions of 4 elements per member)

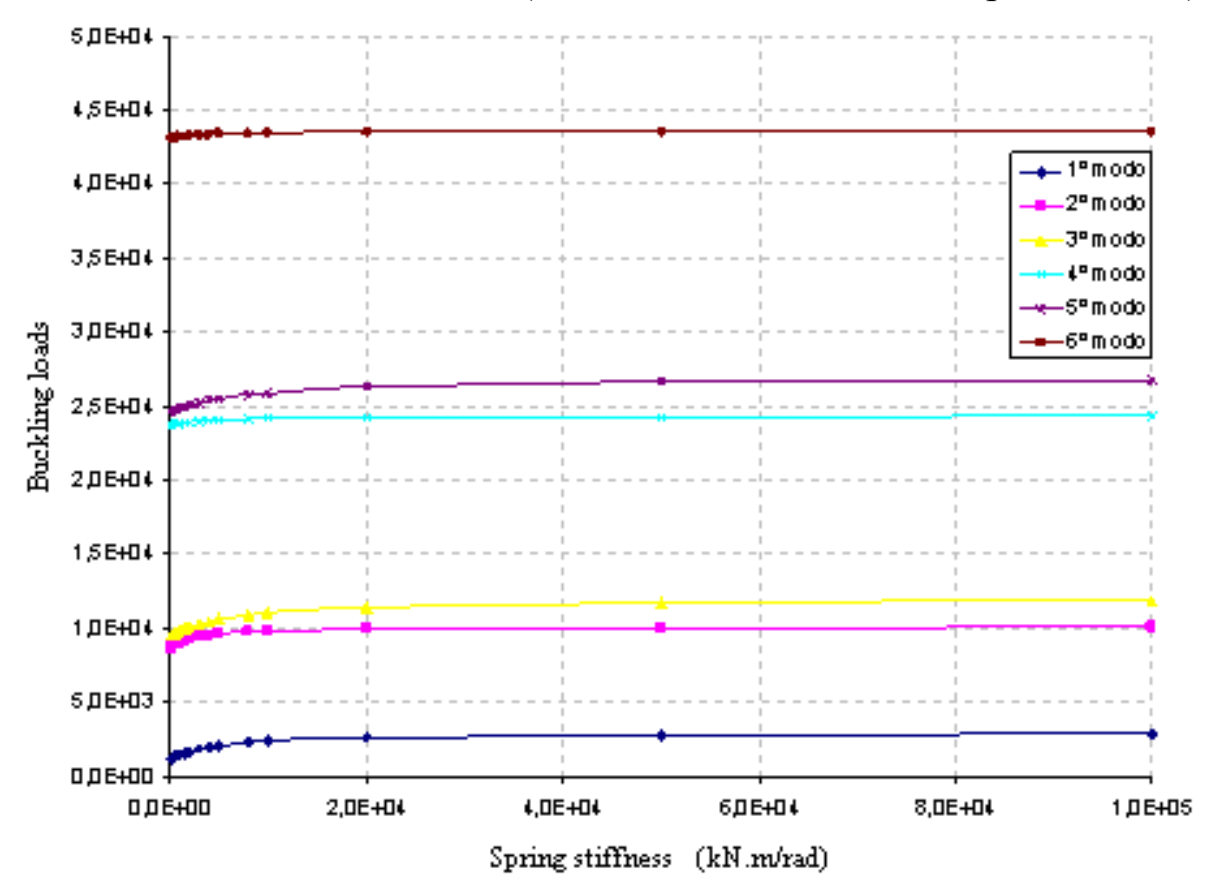

Figure 8: Buckling loads of sidesway free frame $v s$ spring stiffness of the beam to column connections 
The gain in carrying capacity for the critical mode of this displaceable joints frame as spring stiffness increases from $10^{4}$ to $10^{10}$ is smaller than $20 \%$; indirectly this may be considered as an upper bound on the gain in carrying capacity for this sidesway free frame, if semi-rigid connections would have been modelled for the links between the beam and the columns (Cesar and Barros [10]).

\section{Eurocode 3 criteria for $2^{\text {nd }}$ order analyses}

To complete this section a design code remark (from Eurocode 3 - EC3 [11] [12]) must be made, to ensure that in this study is guaranteed the structure serviceability. In this design code a $2^{\text {nd }}$ order analyses is not necessary when the structure is braced in such a way that the lateral displacement is reduced in $80 \%$ relatively to the unbraced configuration (Figure 9) and also when the structural system can be classified as an un-sway frame, which is the same as $\alpha_{\text {crit }} \geq 10$ (Figure 10).
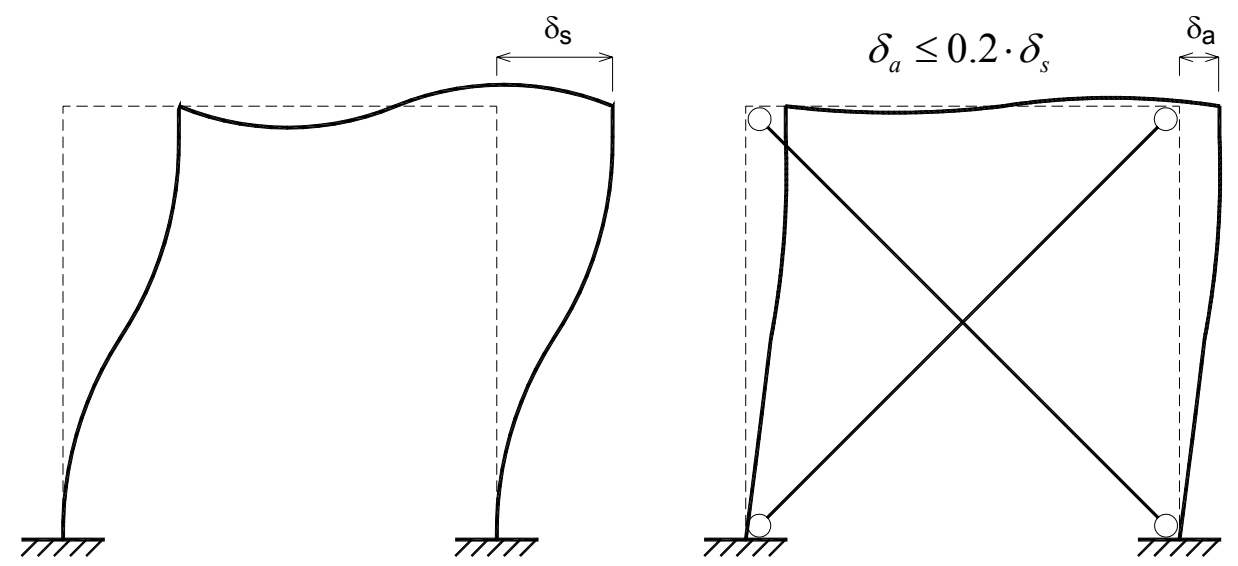

Figure 9: Eurocode 3 braced frame classification criteria

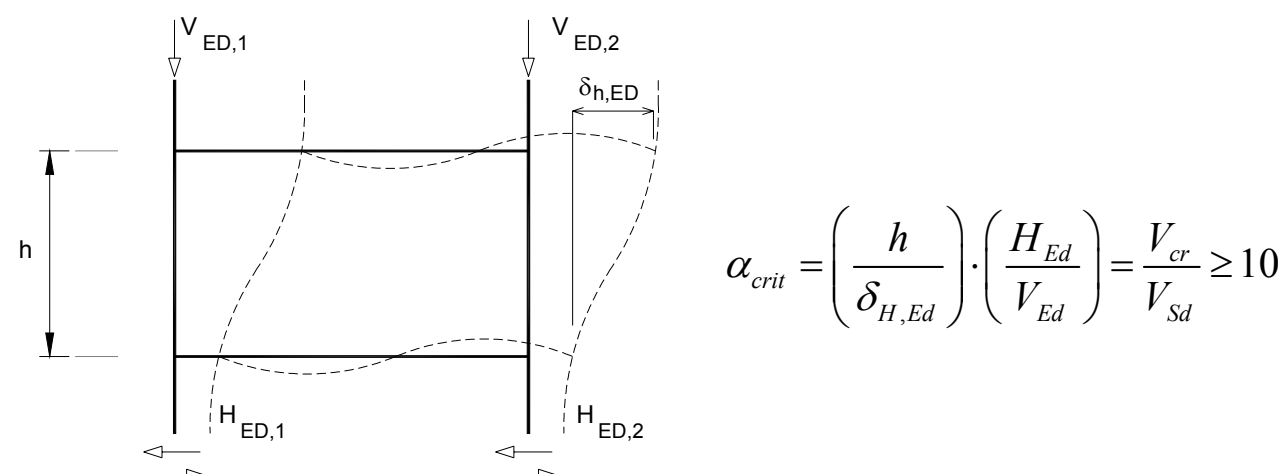

Figure 10: Eurocode 3 un-sway classification criteria

These criteria were used in this work to ensure the efficiency of the bracing system selected. When the structure is classified as a sway frame, EC3 allows performing a simplified $2^{\text {nd }}$ order analysis like the moment magnification method (only for $\mathrm{V}_{\text {sd }} / \mathrm{V}_{\text {cr }} \leq 0.25$ ). 
The usage of these methods for the design practice of $2 \mathrm{D}$ frames is a huge limitation when the designer needs to analyse asymmetric 3D rectangular structures or 3D structures with unusual complex geometry. For these, the best technique is to do a $2^{\text {nd }}$ order $3 \mathrm{D}$ analysis and calculate the carrying capacity in the true deformed configuration, neglecting the sway classification.

According to the EC3, the structural serviceability can be verified limiting the inter-story drift by the allowed code drift (usually limited to $\mathrm{H} / 300$, in which $\mathrm{H}$ is the inter-story height). So the validity of the classification criteria used in EC3 can be ascertained through this study, however the structure calculated carrying capacity (using authors INST3D, ANSYS or SAP 2000) is independent of this classification.

\section{Parametric Study on the Carrying Capacity of 3D Frames with Plan and Elevation Asymmetries}

After software calibration some parametric studies have been elaborated on the carrying capacity of geometrically non-linear 3D steel frames. One of the analyzed structures is a 5-floor 3D reference frame with plan asymmetry, braced and unbraced, whose initial results were previously presented by Barros and Cesar [3].

In Figure 11 the perspective view of the asymmetric building is shown with the indication of the numbering of the $2 \mathrm{D}$ frames that compose the represented 3D structure. This figure also gives the column profiles of HE series, allocated to each floor of the modelled 2D frames.

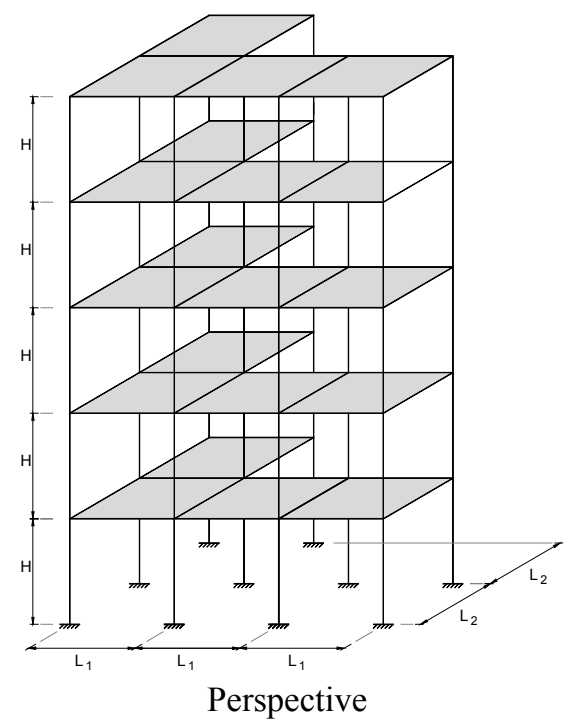

\begin{tabular}{|c|c|c|c|c|c|}
\hline & $\begin{array}{c}\text { Floor } \\
\mathbf{1}\end{array}$ & $\begin{array}{c}\text { Floor } \\
\mathbf{2}\end{array}$ & $\begin{array}{c}\text { Floor } \\
\mathbf{3}\end{array}$ & $\begin{array}{c}\text { Floor } \\
\mathbf{4}\end{array}$ & $\begin{array}{c}\text { Floor } \\
\mathbf{5}\end{array}$ \\
\hline P1 & $200 \mathrm{~A}$ & $200 \mathrm{~A}$ & $180 \mathrm{~A}$ & $180 \mathrm{~A}$ & $160 \mathrm{~A}$ \\
\hline P2 & $220 \mathrm{~A}$ & $220 \mathrm{~A}$ & $200 \mathrm{~A}$ & $180 \mathrm{~A}$ & $140 \mathrm{~A}$ \\
\hline P3 & $220 \mathrm{~A}$ & $220 \mathrm{~A}$ & $200 \mathrm{~A}$ & $180 \mathrm{~A}$ & $140 \mathrm{~A}$ \\
\hline P4 & $200 \mathrm{~A}$ & $200 \mathrm{~A}$ & $180 \mathrm{~A}$ & $180 \mathrm{~A}$ & $160 \mathrm{~A}$ \\
\hline P5 & $220 \mathrm{~A}$ & $220 \mathrm{~A}$ & $200 \mathrm{~A}$ & $180 \mathrm{~A}$ & $140 \mathrm{~A}$ \\
\hline P6 & $240 \mathrm{~A}$ & $220 \mathrm{~A}$ & $200 \mathrm{~A}$ & $180 \mathrm{~A}$ & $140 \mathrm{~A}$ \\
\hline P7 & $220 \mathrm{~A}$ & $220 \mathrm{~A}$ & $200 \mathrm{~A}$ & $180 \mathrm{~A}$ & $140 \mathrm{~A}$ \\
\hline P8 & $200 \mathrm{~A}$ & $200 \mathrm{~A}$ & $180 \mathrm{~A}$ & $180 \mathrm{~A}$ & $160 \mathrm{~A}$ \\
\hline P9 & $200 \mathrm{~A}$ & $200 \mathrm{~A}$ & $180 \mathrm{~A}$ & $180 \mathrm{~A}$ & $160 \mathrm{~A}$ \\
\hline P10 & $200 \mathrm{~A}$ & $200 \mathrm{~A}$ & $180 \mathrm{~A}$ & $180 \mathrm{~A}$ & $160 \mathrm{~A}$ \\
\hline \multicolumn{5}{|c|}{ Characteristics of the HE column series used }
\end{tabular}

Figure 11: Perspective view of the 3D reference frame with plant asymmetry

The parametric analysis on the values of the critical load parameter is based upon the variation of the length of the beam members (frame spans $L_{1}$ and $L_{2}$ ) between the columns and on the definition of the space geometry of the structure (frame inter-story height $\mathrm{H}$ and number of floors with slab L3). 


\subsection{Critical loads evolution vs changes of frame spans and inter- story height}

Two load situations on the columns had been considered earlier (Figure 12): Case 1 - Even equal unit loads; Case 2 - Uneven loads proportional to the area of influence of the columns.
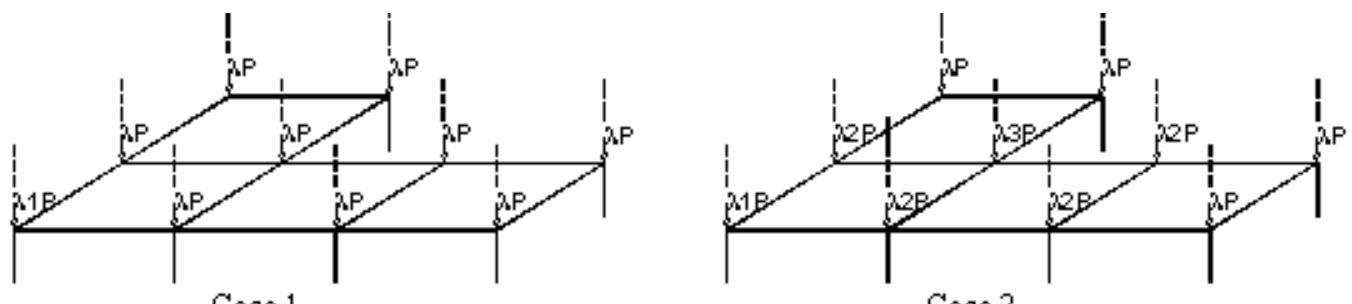

Figure 12: Load cases on the columns: Case 1 - even ; Case 2 - uneven

The 3D structure was analysed with unbraced and braced configurations, the latter using pinned diagonals with null flexural stiffness and with an area of $11 \mathrm{~cm}^{2}$ corresponding to the metallic profiles of series UPN (UPN-80), smaller than the adopted for the beams and columns. The localization of the diagonal braces was studied in order to maximize the bracing effect for the 3D asymmetric frame.

Some results of the critical buckling loads for the 3D frame in Figure 11 (with $\mathrm{L}_{1}=\mathrm{L}_{2}=\mathrm{L}$ ) published earlier by Barros and César [3] are herein quickly reviewed in Figures 13 to 15 , just for comparison with the ones that will follow in the next paragraph of the article.

(a) Unbraced 3D frame

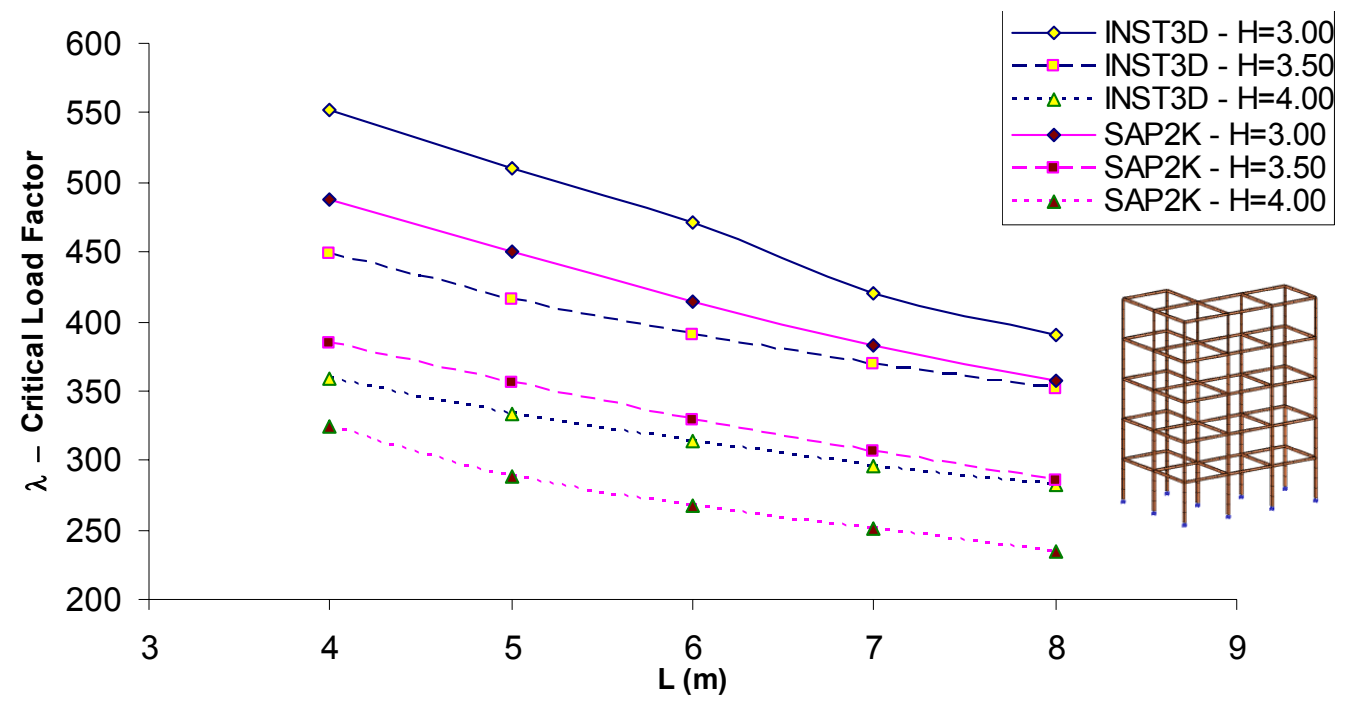

Figure 13: Parametric results of critical load factors obtained by INST3D and SAP 2000 , for the un-braced frame with equal nodal vertical loads $\lambda \mathrm{P}$ 
(b) Braced 3D frame (Case 1: Even equal unit loads)

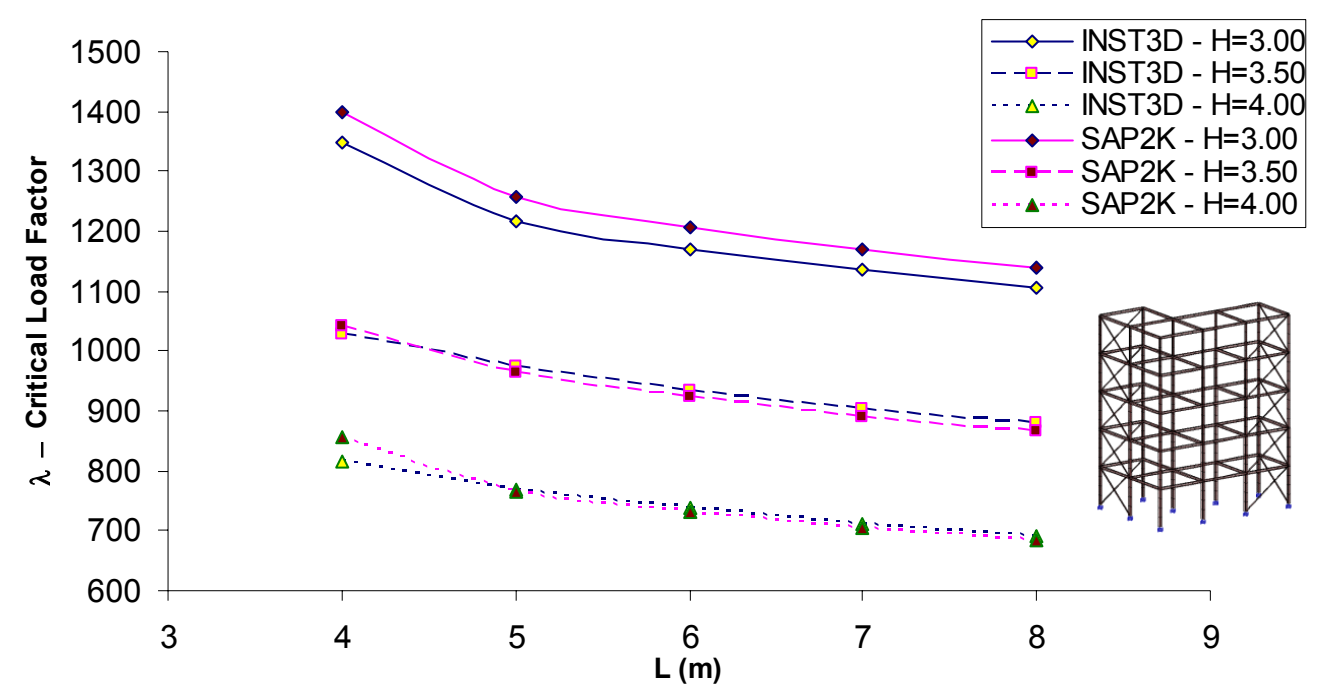

Figure 14: Parametric results of critical load factors obtained by INST3D and SAP 2000 , for the braced frame with even equal nodal vertical loads $\lambda P$

(c) Braced 3D frame (Case 2: Uneven loads proportional to the influence area)

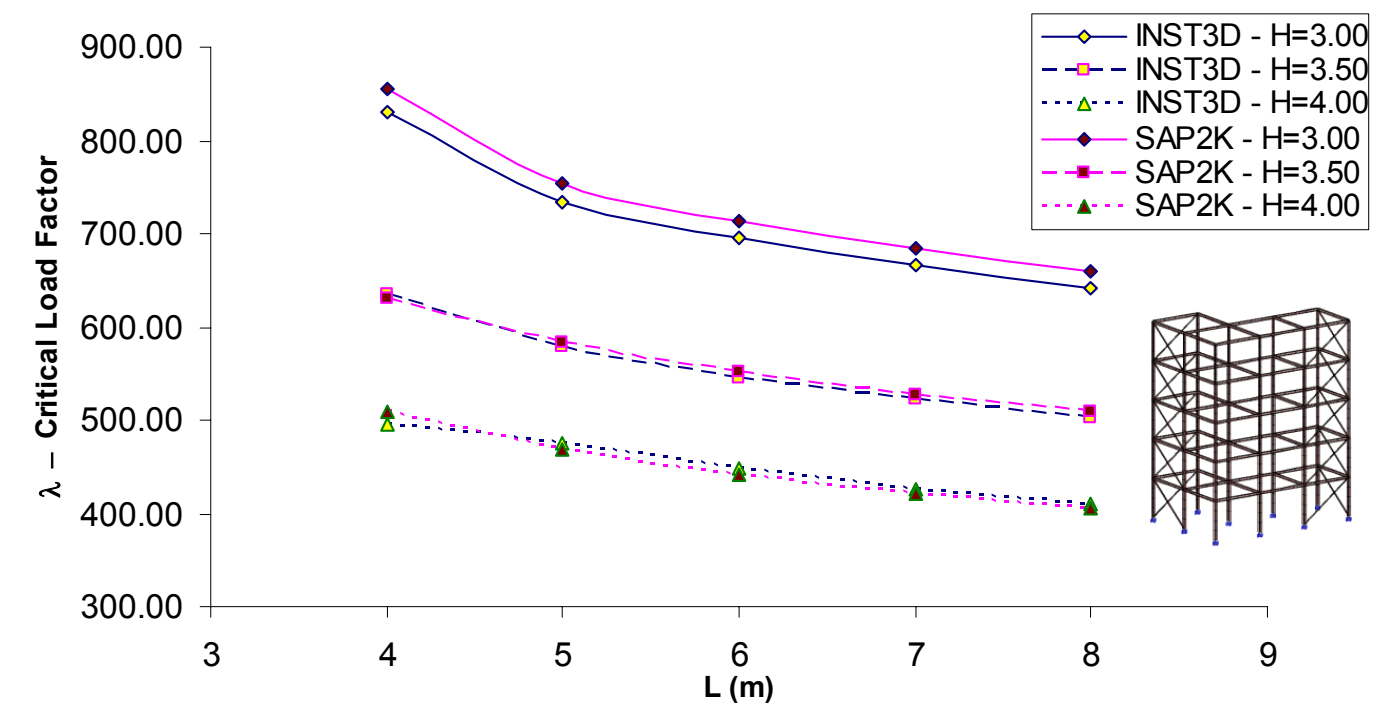

Figure 15: Parametric results of critical load factors obtained by INST3D and SAP 2000 , for the braced frame with uneven nodal vertical loads $\lambda \mathrm{P}, 2 \lambda \mathrm{P}, 3 \lambda \mathrm{P}$

It was verified that results obtained with the authors INST3D software were always conservative since they estimate non-linear global carrying capacities (global critical load factors) of this braced asymmetric 3D reference frame with values lower than the SAP 2000 results $(3-4 \%$ lower for $\mathrm{H}=3 \mathrm{~m}$; much less in the other cases). Moreover both methodologies are close enough, justifying the use of the diaphragm constraint option to model rigid plane diaphragm in SAP 2000. 


\subsection{Critical loads evolution associated to elevation asymmetries}

In this paragraph are determined the critical buckling loads of the 3D frame initially represented in Figure 11, but now associated with an additional variation - the elevation asymmetry - due to the inclusion of the rigid diaphragm slab L3 solely in a certain number of floors. For load case 2, the parametric study also includes varying the span between columns $(\mathrm{L})$ and the inter-story height $(\mathrm{H})$. The six parametric cases of elevation asymmetry represented in Figure 16 were considered by Cesar [9] Cesar and Barros [10], in unbraced and braced configurations.
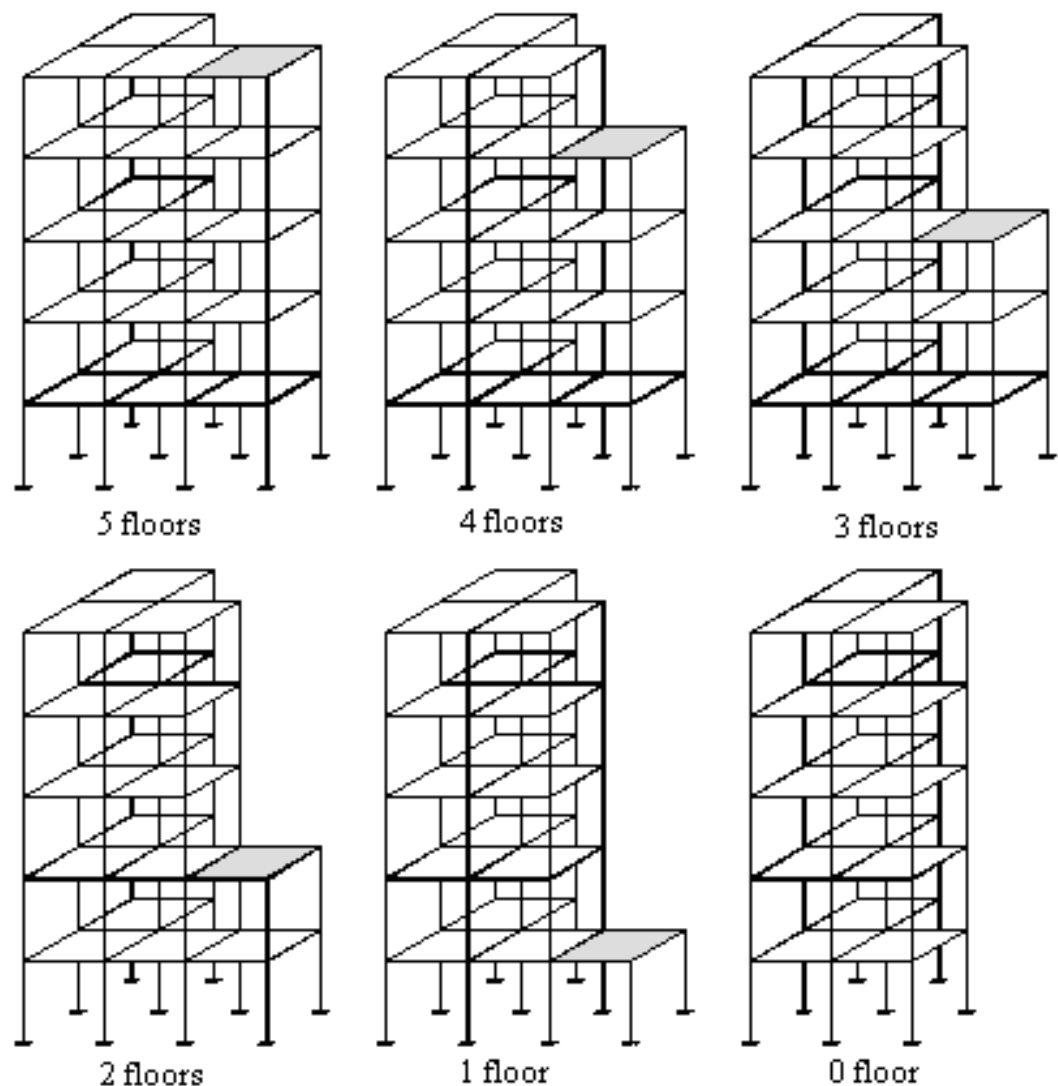

Figure 16: Six parametric cases using slab L3, to ascertain Elevation Asymmetry

Some significant results have been graphically synthesized in Figures 17 to 19, comparing the evolution of critical buckling loads of the six elevation asymmetry cases, unbraced and braced, for three inter-story heights and six frame spans.

The elevation asymmetry plays a very important role in the parametric study, since the number of floors with the rigid diaphragm slab L3 significantly changes the non-linear geometric carrying capacity of the 3D reference frame.

For unbraced configurations, it is verified that the value of the critical buckling load increases with the number of floors of slab L3 until reaching a maximum value for 2 slab floors; for 3 slab floors the carrying capacity is practically of the same value, but when more than 3 slab floors are used a loss of the carrying capacity is observed. 
For braced configurations, a continuous increase of the critical buckling load with the number of floors of slab L3 is distinctively observed: the carrying capacity practically doubles, for the range of parametric studies analysed.
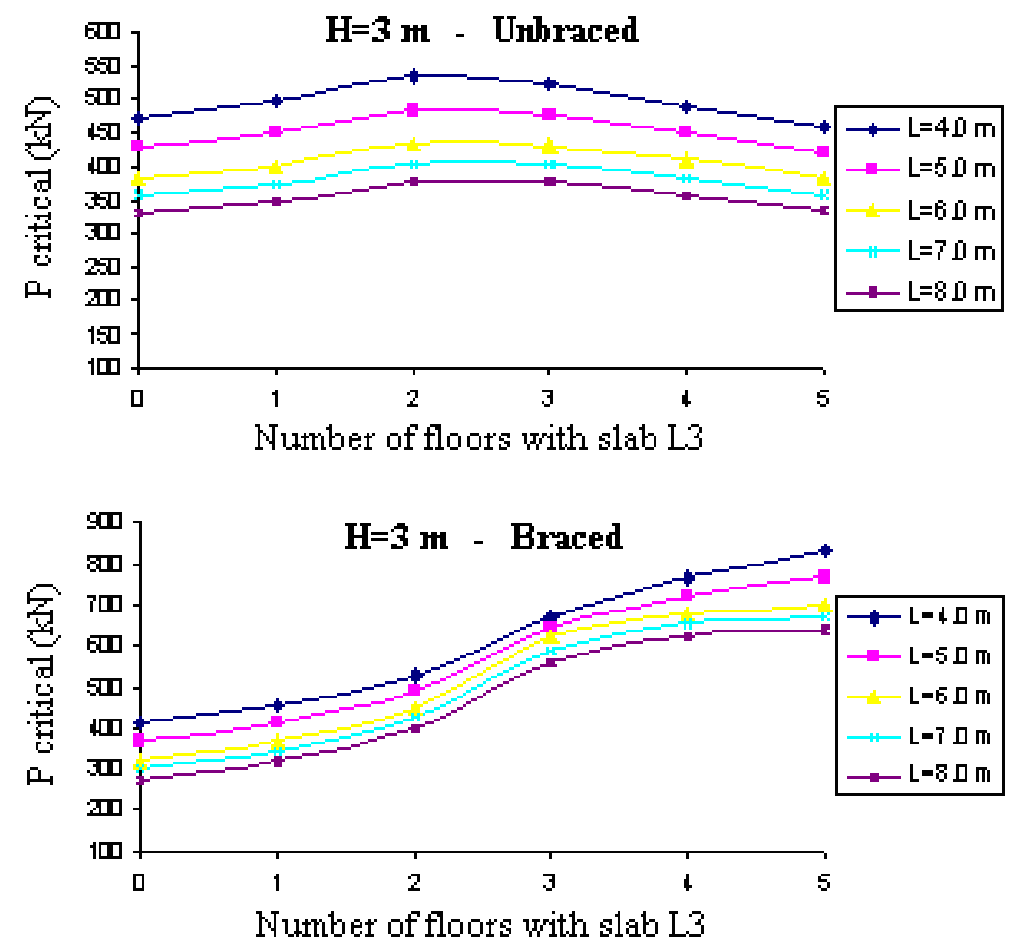

Figure 17: Slab L3 - parametric variation with \# floors and $\operatorname{span}(\mathrm{H}=3.0 \mathrm{~m})$
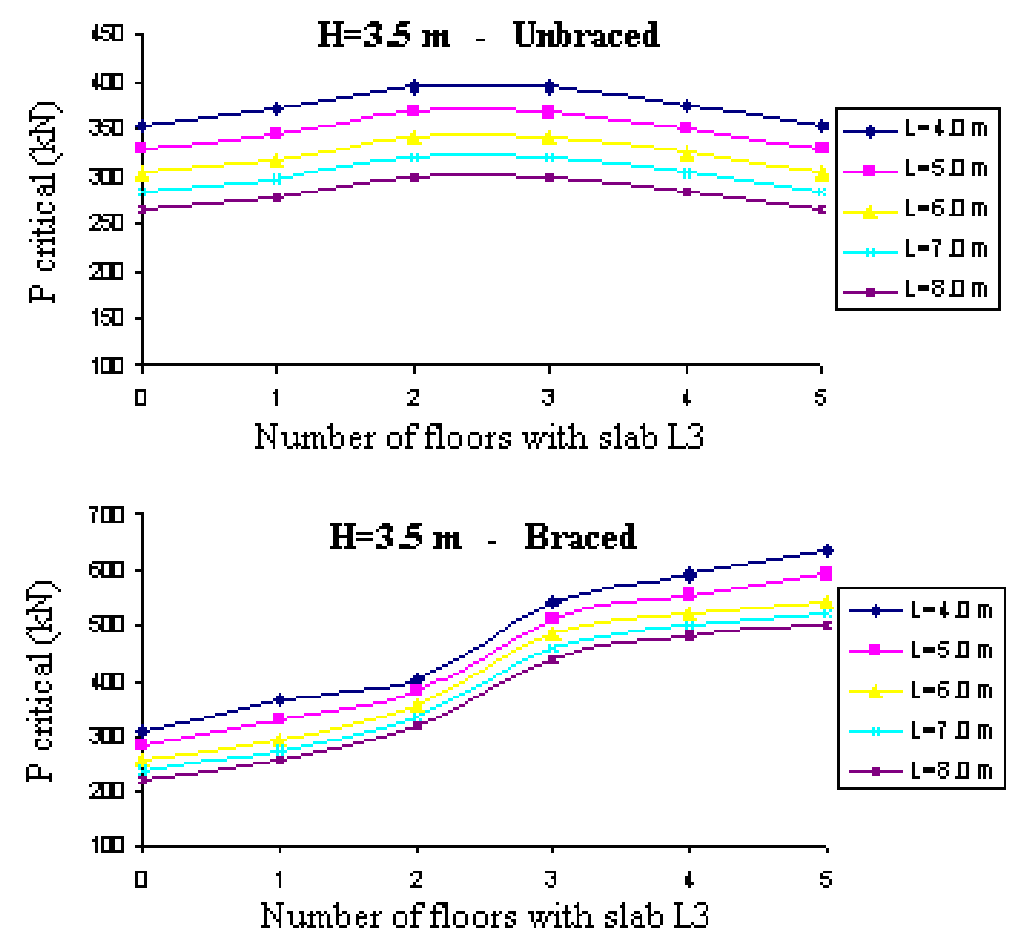

Figure 18: Slab L3 - parametric variation with \# floors and $\operatorname{span}(\mathrm{H}=3.5 \mathrm{~m})$ 

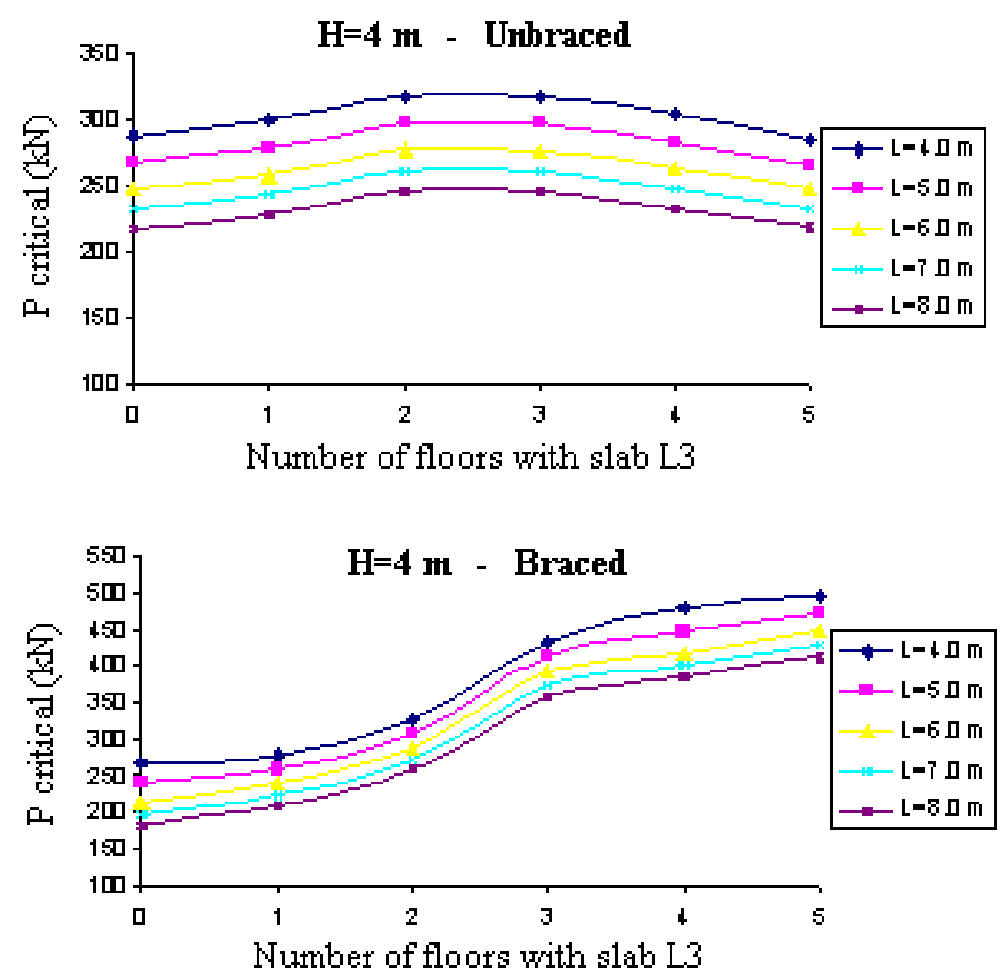

Figure 19: Slab L3 - parametric variation with \# floors and span $(\mathrm{H}=4.0 \mathrm{~m})$

For the unbraced 3D reference frame, the loss of stability occurs for a deformation pattern in the direction of smaller inertia, with translation and rotation of the rigid slab diaphragms as a displaceable joints frame. The use of the rigid slabs L3 induces a stabilizing stiffening effect up to 2 floors by increasing the rigidity in the direction of the smaller inertia of the columns, therefore insuring an initial slight increase of carrying capacity; however as the rigid slabs L3 are further used in elevation, the 3D tall building character of a displaceable joints frame comes upon and the carrying capacity is controlled by the sidesway free configuration of the unbraced 3D reference frame.

The placing of bracings controls significantly the overall global structural behaviour. For the efficiently braced 3D reference frame, the stabilizing stiffening effect of the rigid slabs L3 insures a continuous increase of carrying capacity; this stiffening effect is more effective in lower stories.

Coherence of results was also found for other equivalent representations of the evolution of the critical buckling load factors of the parametric study done for the given reference frame; a parametric study for the same frame, on the carrying capacity and non-linear geometric behaviour, associated with the elevation asymmetry in the two slabs L2 and L3 was also successfully achieved by Cesar [9]. Moreover for a distinct asymmetric 10-story 3D frame (with a T-plan layout) similar results, evolution of buckling loads and conclusions where also coherently observed. 


\section{Conclusions}

The accuracy of the developed software INST3D was further surveyed, validating its use to predict critical buckling loads of 3D rectangular frames, unbraced and braced. Relatively to some available commercial software used in the evaluation of the critical load parameter, it was verified that ANSYS, LUSAS and SAP 2000 give results in this order of lesser accuracy; the numerical errors (due to the intrinsic formulations used in each of these programs) can be decreased by increasing the degree of discretization of the frame members in bar elements.

The modelling of the nodes in a macro-zone, using laminar shell finite elements, revealed to be very effective in understanding the stiffening effect of added metallic plates in the connection zone between structural members, and provided accurate coherent buckling loads of a calibration frame. Also the use of elastic spring models at the connections of beam to columns, with spring constant values ranging from intermediate to very stiff springs, provided coherent solutions for the buckling loads of a calibration frame. Also if semi-rigid connections would have been modelled for the links between the beam and the columns of the calibration frame, an upper bound for the gain in carrying capacity for sidesway prevented and sidesway free frames is around $15 \%-20 \%$.

The rational use of the bracing elements controls structural performance of distinct structural designs. For the braced asymmetric 3D reference frame, the results obtained with the authors INST3D software with exact total stiffness formulation were always conservative as compared with SAP 2000 results. But both methodologies are close enough, justifying the use of the diaphragm constraint option to model rigid plane diaphragm slabs in SAP 2000. The behaviour of the reference $3 \mathrm{D}$ frame must be commanded by the $2 \mathrm{D}$ frame that presents greater carrying capacity. In this in case, the frame presents a behaviour of the type of undisplaceable joints sidesway prevented structure.

For the elevation asymmetry case, increasing the number of rigid slabs may not necessarily imply an increase of the carrying capacity of the structure, if the 3D asymmetric structure is of the type of displaceable joints sidesway free. Such increase in carrying capacity can only be verified for un-displaceable joints sidesway prevented structures.

If the $3 \mathrm{D}$ asymmetric tall structure has elevated zones, the configuration of these substructures may condition the global carrying capacity. The carrying capacity of these elevated zones is crucial for the overall performance of the structure, especially if it is of the unbraced displaceable joints sidesway free type. The configuration that insures a better geometric non-linear behaviour and carrying capacity usually emphasizes a pyramidal elevation layout.

\section{References}

[1] CTBUH, "Advances in Tall Buildings", Editor-in-Chief: L.S. Beedle, Council on Tall Buildings and Urban Habitat, Van Nostrand Reinhold Company Inc., New York, 1986. 
[2] César M.B. and Barros R.C., "Modelos de Comportamento Não Linear Geométrico de Pórticos Assimétricos Tridimensionais", (Models of Geometric Non-linear Behavior of Three-Dimensional Asymmetric Frames), Editors: C. Soares, A. Baptista, G. Bugeda, M. Casteleiro, J. Goicolea, J. Martins, C. Pina, H. Rodrigues, Congress of Computational Methods in Engineering, Área Temática: Estabilidade e Análise Não Linear de Estruturas Metálicas, 15 pp., APMTAC, Lisbon, Portugal, 2004.

[3] Barros R.C. and Cesar M.B., "Non-Linear Carrying Capacity of Asymmetric Three-Dimensional Braced Steel Frames", Editors: B. Topping and C. Mota Soares, Proceedings of The Seventh International Conference on Computational Structures Technology, Lisbon, Portugal, Paper 145, Civil-Comp Press, Scotland, U.K., 2004.

[4] ANSYS, “ANSYS Release 8.0 Documentation”, ANSYS Inc., Canonsburg, Pennsylvania, USA, 2003.

[5] LUSAS, "Powerful FE Technology for Specialist Applications", Theory Manual 1 - Theory Manual 2 - Verification Manual, Version 13, UK, 2004.

[6] SAP, "SAP 2000 Software Verification", Computers and Structures Inc., Berkeley, California, USA, 2003.

[7] Barros R.C. and Cesar M.B., "Manual on the use of program INST3D for the instability of three-dimensional rectangular frames under vertical loads" (in Portuguese), Structural Division, Department of Civil Engineering, FEUP, Porto, Portugal, 2003.

[8] A.J. Reis and D. Camotim, "Estabilidade Estrutural", McGraw-Hill de Portugal, Lisbon, 2001.

[9] César M.B., "Estudos Paramétricos sobre a Instabilidade de Pórticos Metálicos Bidimensionais e Tridimensionais", Tese de Mestrado em Estruturas de Engenharia Civil, Department of Civil Engineering, FEUP, Porto, Portugal, Dezembro 2004.

[10] César M.B. and Barros R.C., "Modelação de Ligações em Pórticos Associada a Estudo Paramétrico do Comportamento Não Linear Geométrico de Pórticos Metálicos Tridimensionais Assimétricos", (Modelling of Connections in Frames Associated with a Parametric Study of the Geometric Non-linear Behaviour of Metallic Three-Dimensional Asymmetric Frames), Congreso de Métodos Numéricos en Ingeniería 2005, Granada, 4-7 July 2005, SEMNI, Spain, 2005 (in-press).

[11] ECCS, "Essentials of Eurocode 3: Design Manual for Steel Structures in Building", European Convention for Constructional Steelwork, ECCS Advisory Committee 5 - Application of Eurocode 3, $\mathrm{N}^{\mathrm{o}} 65,1^{\text {st }}$ edition, Brussels, Belgium, 1991.

[12] CEN prEN 1993-1-1, "Eurocode 3: Design of Steel Structures - Part 1-1 General rules and rules for buildings", Stage 34 draft, European Committee for Standardisation, Brussels, Belgium, 2003. 